\title{
In Memoriam: Pierre J. Meunier
}

\author{
R. D. Chapurlat ${ }^{1} \cdot$ G. Boivin ${ }^{1}$
}

Published online: 20 June 2016

(C) International Osteoporosis Foundation and National Osteoporosis Foundation 2016

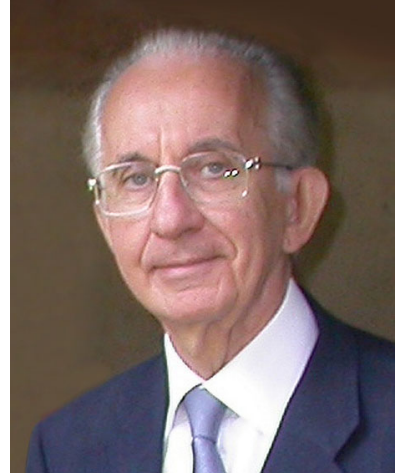

Our community has lost an exceptional clinician, researcher, and teacher. Professor Pierre J. Meunier passed away on 8 May 2016 at the age of 79.

Pierre J. Meunier was a pioneer of research into bone diseases, among those who de facto founded this research and clinical field in the 1960s and 1970s. His research work started with his MD dissertation on dynamics of bone remodeling in 1967. This work was among those that introduced histomorphometry to the bone field. He explored the pathophysiology of bone diseases, bone loss associated with aging, and postmenopausal osteoporosis. During the 1980s and 1990s, he participated in the development of new medications to treat osteoporosis, Paget's disease of bone, and fibrous dysplasia of bone. For instance, he described the anabolic effect of intermittent parathyroid hormone 20 years

This obituary is being published jointly in Osteoporosis International and Archives of Osteoporosis.

R. D. Chapurlat

roland.chapurlat@inserm.fr

1 INSERM UMR 1033, Université de Lyon, Hôpital E Herriot, 69008 Lyon, France before it was marketed to treat osteoporosis, in the form of teriparatide. He also provided histomorphometric studies in clinical trials of fluoride, strontium ranelate, SERMs, and bisphosphonates. In this context, he was the founding father of a great laboratory of histomorphometry in Lyon, France, as well as the INSERM unit 234, which later evolved towards unit 403, unit 831 , and, today, unit 1033 . There, he trained many researchers and physicians from many countries. One of his main qualities was his ability to pick up the right research questions from clinical practice, test them in the lab, and go back to the clinic with new diagnostic approaches or treatments.

Pierre J. Meunier published 380 articles and various book chapters. He received several prizes, including the John Haddad Prize from IBMS, the Frederic C. Bartter Award from ASBMR, and the Pierre Delmas Prize from ESCEO-IOF. He was also Officer of the Palmes Académiques and the first president of the GRIO, the French society for bone diseases.

More importantly, he had a humanist behavior that was unique. This is long remembered by all those who worked with him in research and in the rheumatology division that he led for over 15 years. His patients deeply appreciated his courtesy and still ask for news 15 years after his retirement. One important discovery - the use of bisphosphonates to treat fibrous dysplasia of bone - stems from his sense of humanist medical care. Indeed, a family member was affected by this disease, so this became a personal challenge. His clinical skills were simply impressive, and he was often able to reach difficult diagnoses with a well-conducted history, physical examination, and simple radiographs. He was a gentleman and, when disagreements arose between those with whom he worked, he would explain his position in refined and diplomatic terms. And of course, the work was punctuated by frequent sophisticated deadpan jokes!

Professor Meunier, all those you educated and worked with thank you. 